\title{
Aprendizagem de ciências no jogo digital Plague Inc.: análise de conteúdo em uma comunidade de jogadores
}

\author{
Taynara Rúbia Campos ${ }^{1}$ \\ Daniela Karine Ramos ${ }^{1}$ \\ Cláudia Regina de Brito ${ }^{1}$ \\ ${ }^{1}$ Universidade Federal de Santa Catarina (UFSC), Brasil.
}

Resumo. O século XXI trouxe consigo discussões sobre o papel da educação frente a popularização das tecnologias de informação e comunicação, incluindo o ensino e a aprendizagem de ciências. Nesse contexto, os jogos digitais, que são desenvolvidos com base em potentes estratégias de aprendizagem e gamificação, se tornam objetos culturais potentes em promover aprendizagens diversas, que complementam os processos de ensino-aprendizagem na sala de aula. Assim, essa pesquisa teve como objetivo averiguar a aprendizagem de ciências em uma comunidade de jogadores do jogo digital sobre pandemias Plague inc., através da análise do conteúdo de 243 avaliações dos mesmos sobre o jogo, estas categorizadas em seis subcategorias relacionadas ao aprendizado de ciências. Os resultados demonstram o potencial do jogo digital Plague inc. e das práticas de sua comunidade online no desenvolvimento de saberes variados, desde atitudes até conceitos científicos, além de promover o conhecimento prático sobre a relação entre ciências e a sociedade e a interação crítica e criativa entre jogadores da comunidade.

Palavras-chave: aprendizado baseado em jogos digitais; educação em ciências; jogos digitais.

El aprendizaje de las ciencias con el juego digital Plague Inc.: análisis de contenidos en una comunidad de jugadores

Resumen. El siglo XXI trajo consigo debates sobre el papel de la educación ante la popularización de las tecnologías de la información y la comunicación, incluyendo la enseñanza y el aprendizaje de las ciencias. En este contexto, los juegos digitales, que se desarrollan en base a potentes estrategias de aprendizaje y gamificación, se convierten en poderosos objetos culturales en la promoción de diversos aprendizajes, que complementan los procesos de enseñanza-aprendizaje en el aula. Así, esta investigación tuvo como objetivo investigar el aprendizaje de las ciencias en una comunidad de jugadores del juego digital sobre pandemias Plague inc. Los resultados demuestran el potencial del juego digital Plague inc. y las prácticas de su comunidad online en el desarrollo de conocimientos variados, desde actitudes hasta conceptos científicos, además de promover conocimientos prácticos sobre la relación entre ciencia y sociedad y la interacción crítica y creativa entre los jugadores de la comunidad.

Palabras clave: aprendizaje digital basado en juegos; educación científica; juegos digitales.

Science learning on the digital game Plague Inc.: content analysis in a player community Abstract. The 21st century brought with it discussions on the role of education in the face of the popularization of information and communication technologies, including science teaching and learning. In this context, digital games, which are developed based on powerful learning strategies and playability, become powerful cultural objects in promoting diverse learning, which complement the teaching-learning processes in the classroom. Thus, this research aimed to investigate science learning in a community of players of the digital game about pandemics Plague inc. The results demonstrate the potential of the digital game Plague inc. and the practices of its online community in the development of varied knowledge, from attitudes to scientific concepts, in addition to promoting practical knowledge about the relationship between science and society and critical and creative interaction between community players. Keywords: digital game-based learning; science education; digital games.

\section{Introdução}

Os jogos digitais referem-se a um universo de formas e possibilidades que proporcionam experiências diversificadas nas interações que se estabelecem entre os jogadores, a interface e o conteúdo neles veiculado. A compreensão dessas interações e seus desdobramentos, no que diz respeito à aprendizagem e suas consequências, têm sido tema de interesse e objeto de pesquisas. Nesse sentido, compreende-se que a aprendizagem acontece nessas interações, tanto em espaços formais, não formais e informais de educação. Observa-se que muitas crianças, jovens e adultos, 
com experiências regulares de interação com os jogos digitais, modificam seus repertórios de aprendizagem, incluindo a apropriação de conceitos, o desenvolvimento de habilidades e atitudes.

Parte-se da compreensão dos jogos digitais como sistemas compostos por vários elementos que se inter-relacionam -software, hardware e interação lúdica significativa - formando contextos de interação que os jogadores podem manipular, explorar e habitar (Salen \& Zimmerman, 2012). Mais especificamente, os jogos digitais são atividades lúdicas limitadas pelas regras e pelo contexto, o que gera os desafios, fazendo com que o jogador tome decisões e aja de forma relevante (Schuytema, 2017). Ao atuar nos jogos é preciso se adequar às regras e costumes, explorar e descobrir como passar por obstáculos desafiadores, resolver problemas e tomar decisões para alcançar os objetivos apresentados dentro desse mundo digital (Ramos, 2013).

Os jogos digitais destacam-se pelo nível de envolvimento que provoca no jogador, que se mantém persistente nas tarefas por longo tempo, o que evidencia as qualidades motivacionais dos jogos (Tobias et al., 2014). Partindo do pressuposto que o jogo digital se caracteriza por ser uma experiência imersiva e atrativa para os jogadores que resulta em aprendizagens, neste artigo investigamos um conjunto de postagens realizadas em uma comunidade online de jogadores do Plague inc. para analisar suas percepções sobre as aprendizagens decorrentes da interação com o jogo digital.

Este artigo volta-se às reflexões feitas pelos jogadores, sobre suas aprendizagens e experiências ao interagir com o jogo, resgatando, comparando e compartilhando conhecimentos formais de ciências biológicas com os outros membros da comunidade online da qual participam. Entende-se que a aprendizagem com jogos digitais deve considerar os espaços relacionados a eles e habitados por seus jogadores. Nesse caso, o espaço da comunidade pode se configurar em uma forma interativa de se vivenciar, pensar e discutir sobre ciências, em variados contextos, de diferentes maneiras e abordagens.

\section{Comunidades e aprendizagem com jogos digitais}

A Base Nacional Comum Curricular (BNCC), parâmetro mais recente para a educação brasileira, caracteriza os jogos como recursos de aprendizagem e como práticas culturais. Desse modo, no documento, os jogos digitais aparecem como um recurso separado dos outros jogos, inclusive reconhecendo a importância de entendêlos como fenômenos culturais, sociais e de aprendizagem. Essa compreensão é apresentada em forma de objetivos pedagógicos, sendo: a experimentação dos mesmos dentro e fora da escola, a compreensão e valorização dos significados atribuídos a esses recursos por diferentes grupos sociais, a identificação das transformações tecnológicas envolvidas e a relação deles com jogos analógicos, experiências corporais e a cultura (Ministério da Educação, 2018).

Nesse contexto, não é de surpreender que os jogos digitais, como possibilidade educacional, encontram lugar nas práticas e nas pesquisas em educação. No levantamento realizado em 2017, foram produzidos em torno de 460 jogos digitais para o uso na escola, demonstrando o reconhecimento da indústria nesse tipo de objeto de aprendizagem (Sakuda \& Fortim, 2018). Segundo Clark e colaboradores (2016), es- 
tudos sobre jogos digitais inicialmente se concentravam nos impactos negativos, como agressividade, alienação e vício. Os autores complementam que as consequências positivas e o potencial para a aprendizagem despertaram interesse de pesquisadores a partir dos anos 1990, com crescimento nos anos 2000.

No contexto da pesquisa com jogos digitais e seus potenciais para a educação, Gee (2010) listou inicialmente 36 princípios de aprendizagem presentes nos jogos digitais, sendo reorganizados posteriormente em 16 princípios. Para ele, a aprendizagem que ocorre com os jogos digitais é crítica, reflexiva e ativa, pois os elementos e mecânicas do jogo possibilitam reflexão das ações, busca de novas estratégias, ponderação de prós e contras, conhecimento e aceite das regras, além de considerar o contexto social e cultural daquele mundo, dentro e fora do software.

Gee (2003) aponta cinco condições para um jogo digital ser considerado eficiente para a aprendizagem: 1) armazenar experiências e relacioná-las a metas e objetivos claros; 2) valorizar o aprendizado advindo das experiências e ações anteriores a fim de utilizá-las em outros contextos; 3) oferecer feedback imediato possibilitando que o jogador possa reconhecer erros e pensar em como atingir os objetivos de diferentes formas; 4) oportunizar para que os jogadores possam aplicar suas experiências e aprendizados prévios; 5) favorecer a socialização de saberes entre pares, com outros jogadores e mentores.

Destaca-se, ainda, que os jogos digitais têm potencial para alcançar crianças e jovens, permitindo seu crescimento intelectual e social, devido à forma como os conteúdos são apresentados, as metas bem definidas e o convite a resolução contínua de problemas (Squire, 2011). Para Eck (2015), as evidências acumuladas nos últimos 30 anos não deixam dúvidas de que os jogos digitais podem ensinar, considerando mais importantes: o que ensinam, como ensinam e, como utilizá-los.

A incorporação dos jogos digitais na educação pode ser pensada de quatro maneiras, segundo Eck (2015). A primeira refere-se à utilização de serious games ou jogos sérios para ensinar, também utilizar jogos de entretenimento para atingir objetivos educacionais, outra opção é a criação de jogos digitais pelos alunos e, por fim, a gamificação que utiliza os mecanismos e princípios dos jogos em ambientes que não são jogos.

Além desses enfoques destaca-se os jogos digitais como comunidades de prática. Esse foco considera que as tecnologias digitais podem ser entendidas como espaços, seja de convivência, de compartilhamento, de produção, de ativismo, entre outras interações viabilizadas pelo ciberespaço (Backes, 2011). Ademais, entendemos que o mundo dos jogos digitais se estende para outras plataformas, mídias e espaços além do software, onde os jogadores igualmente habitam, o que Zimmerman (2007) chama de "metagame".

Dessa forma, entende-se que jogar um jogo digital vai além de conhecer as regras, objetivos e a interface do jogo, inclui conseguir participar das práticas sociais e comunicacionais a partir dele, como, por exemplo, utilizar linguagem específica, produzir conteúdos e se engajar em práticas que, muitas vezes, são realizadas nas comunidades de jogadores (Zagal, 2008). 
Os jogos digitais apresentam como elemento constitutivo comunidades virtuais que concentram jogares que se comunicam de forma interativa. As comunidades têm como objetivo possibilitar relações de trocas sobre infinitos aspectos circunscritos aos jogos. Elas são forjadas ao longo de processos histórico-sociais e assumem características genuínas, sobretudo por se tratar da convivência entre seres gregários. São muitos os estudos sobre grupos sociais e comunidades. Autores como Tönnies (1973), definem que as comunidades fomentam relações sociais que se estabelecem pelos valores e condutas comuns, com interações orgânicas, pela união, como exemplo, a família, a língua, o território, dentre outros.

Nesse caleidoscópio social, pesquisas apontam elementos comuns definidores de comunidade que remetem ao sentimento de pertencimento, a territorialidade, a permanência e formas específicas de comunicação. Assim, os avanços tecnológicos impõem diferentes formatos de relações sociais, de produção, de convivências ou de habitar, potencializando o imperativo de alargarmos o entendimento de território, de presencialidade, de trocas e aprendizagem.

As comunidades virtuais, se formam e habitam ambientes no ciberespaço que, segundo Recuero (2001), são considerados grupos de pessoas em relação, que se comunicam mediadas por computador, organizadas por afinidades, independente da proximidade física. Estão ancoradas em duas características fundamentais comuns: o valor da comunicação livre e horizontal e o da formação autônoma de redes. Dessa forma, com respaldo em teorias, nos aproximamos do entendimento de comunidades virtuais formadas por interessados e praticantes de jogos digitais. São compostas por grupos que interagem mediados por tecnologias, que habitam o ciberespaço, organizados por afinidades e interesses comuns. Nestas comunidades são trocadas experiências de aprendizagem, baseada na colaboração, onde são utilizadas estratégias horizontais não hierarquizadas, com regras pactuadas que possibilitam a manutenção de laços e, sobretudo, construções identitárias.

\section{Metodologia}

A pesquisa realizada caracteriza-se por ser exploratória e de abordagem qualitativa e busca ampliar a compreensão sobre o que os jogadores aprendem sobre ciências a partir da análise de contribuições espontâneas e participações em uma comunidade online de jogadores. Dessa forma, a análise incluiu jogadores que participam da comunidade online do jogo digital Plague inc., considerando suas postagens na plataforma Steam (https://store.steampowered.com), que divulga e vende jogos digitais, bem como conta com uma comunidade grande de jogadores.

A seleção do jogo digital analisado considerou aspectos que possibilitariam sua integração em contextos educacionais, destacando os conteúdos que podem ser contextualizados, problematizados e explorados na interação com o jogo. Diante disso, os critérios para seleção do jogo observaram a disponibilidade de versão em português gratuita ou semi-gratuita, a compatibilidade com computadores e tablets, comumente utilizados em escolas e, a aderência a conteúdos que poderiam ser abordados em aulas de ciências. Por fim, para base de análise, considerou-se a existência de comunidades de jogares para extração de suas contribuições. 


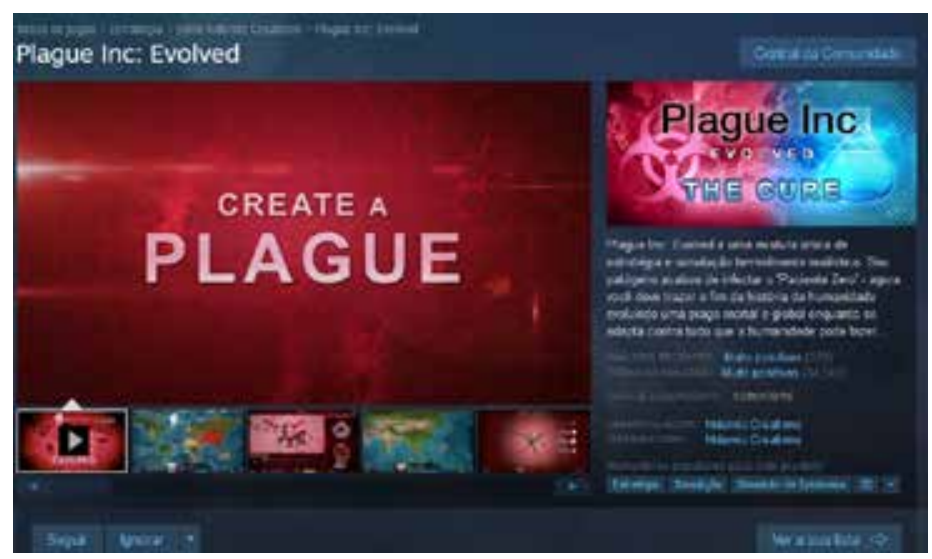

Figura 1. O jogo Plague Inc. está disponível na Plataforma Steam onde os jogadores podem escrever análises sobre o mesmo.

Fonte: https://store.steampowered.com/app/246620/Plague_Inc_Evolved/

A partir disso, o jogo digital selecionado foi o Plague inc., um jogo digital de estratégia criado pela empresa britânica Ndemic Games, onde o jogador precisa criar uma pandemia que destruirá a humanidade. Para isso, ele pode utilizar diferentes organismos, desde bactérias a armas biológicas, mudar as variáveis que deixarão a doença criada mais contagiosa e letal. Entretanto, os humanos tentarão se proteger, por meio de diversas ações como o fechamento de aeroportos, fronteiras e campanhas de prevenção, sobretudo o financiamento de uma vacina. Apesar de o jogo não ter sido criado especificamente para o uso escolar, ele apresenta potencial educacional devido aos conteúdos abordados além de possuir uma comunidade ativa necessária para a análise pretendida.

As avaliações foram coletadas na comunidade online do jogo digital na plataforma Steam, em inglês e em português, do Brasil e de Portugal, publicadas entre janeiro de 2015 e agosto de 2020.

A análise das avaliações pautou-se na análise de conteúdo descrita por Bardin (2011), observando três etapas para a organização: a pré-análise, a exploração do material e o tratamento dos resultados. Na pré-análise realizou-se o contato inicial com o material pela leitura flutuante, para formular hipóteses e elaborar indicadores que norteariam a análise. Na exploração do material os dados foram codificados, trabalhando de forma sistemática com unidades do discurso. Para então, na última etapa, organizar e preparar a apresentação dos resultados.

O total de avaliações iniciais somaram 1734 postagens, sendo 680 pelo filtro de linguagem em inglês, 990 em português do Brasil e 64 em português de Portugal. Após a leitura flutuante 1189 foram excluídas com base nos critérios estabelecidos. Os critérios de exclusão utilizados nessa etapa foram: restringiam-se a elogios ou xingamentos, mensagens que não abordavam aprendizagem e conteúdo de ciências, limitavam-se a expressões, palavras ou letras sem sentido. Esse processo resultou em 545 avaliações que foram analisadas, destas 233 foram codificadas na categoria aprendizagem. 
A leitura flutuante foi realizada em conjunto com anotações iniciais que resultaram na criação e aplicação de categorias para classificar os discursos dos jogadores (Santos, 2012). Na sequência, foi realizada a codificação destes discursos e o agregamento dos códigos que foram progressivamente compondo as subcategorias da categoria "aprendizagem". Como algumas avaliações eram extensas, foram codificados fragmentos textuais de no mínimo uma frase até no máximo um parágrafo, sendo que um mesmo fragmento não poderia pertencer a duas categorias diferentes e a mesma categoria só foi considerada uma vez, se presente, em cada avaliação.

Essa categoria está relacionada aos benefícios de aprendizagem ou atitudes em relação a ciências que foram reportados pelos jogadores em suas avaliações sobre o jogo digital em questão. A caracterização das subcategorias foi baseada no que se observou no material e estão disposta no quadro 1.

Quadro 1. Categoria final relacionada à aprendizagem relatada pelos jogadores.

Subcategorias

Jogo educativo

Educativo sobre ciências biológicas

Educativo sobre outros conteúdos

Reflexão sobre atitudes

Interesse em ciências

Comunidade de aprendizagem
Caracterização no material

Os jogadores consideram o jogo como educativo, sem especificar o conteúdo aprendido.

Relatos sobre o aprendizado de conteúdos relacionados a ciências biológicas.

Relatos sobre o aprendizado de outros conteúdos.

Reflexões sobre mudanças de atitudes que podem ser incentivadas pelo jogo.

Os jogadores relatam o desenvolvimento do interesse em ciências incentivado pelo jogo.

Os jogadores relatam experiências de aprendizagem relacionadas com a comunidade de jogadores.

Fonte: Elaborado pelas autoras (2021).

O projeto foi aprovado pelo comitê de ética da Universidade Federal de Santa Catarina e se encontra sob o número CAAE: 37188720.3.0000.0121. Assim, os nomes de usuário dos jogadores foram transformados em códigos alfanuméricos, a letra representando o país (BR - Brasil, E - países de língua inglesa, P - Portugal) e o número da avaliação, para proteger sua confidencialidade e anonimato e suas falas são utilizadas somente para exemplificar os resultados, sendo algumas traduzidas do inglês.

\section{Resultados e discussão}

A aprendizagem é considerada resultado das experiências que ampliam os repertórios cognitivos, afetivos, atitudinais e comportamentais dos indivíduo. Os jogos digitais cada vez mais configuram-se como experiências que resultam em aprendizagens diversas. Diante disso, a análise desta categoria procurou identificar as percepções e opiniões dos jogadores do Plague Inc., procurando mapear os benefícios relacionados à aprendizagem que são reconhecidos e relatados pelos próprios. No gráfico abaixo é possivel observar as subcategorias e a frequência de ocorrência de cada uma delas nas avaliações feitas pelos jogadores e coletadas na plataforma. 


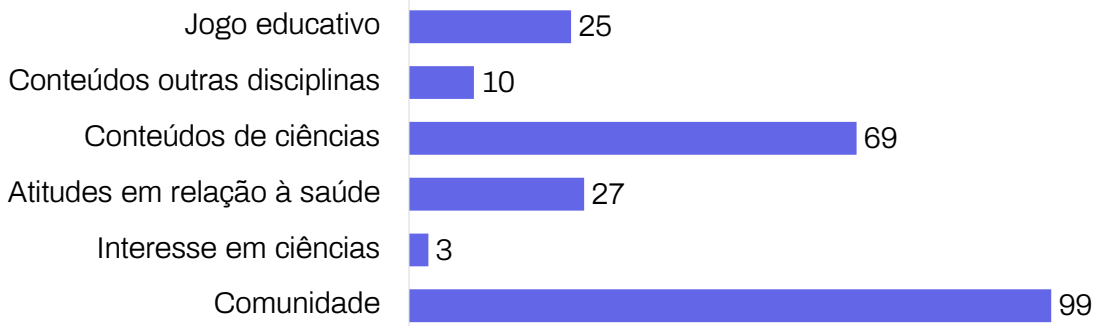

Gráfico 1. Subcategorias de aprendizagem codificadas a partir das postagens dos jogadores.

Fonte: Elaborado pelas autoras (2021)

Como demonstrado no gráfico acima, 25 jogadores consideram o jogo como educativo, sem especificar exatamente um conteúdo aprendido. Entre eles, dois jogadores afirmam que o Plague inc. pode ser uma ferramenta educacional, um afirma que é uma "experiência educacional" e, outros dois, dizem que é um jogo informativo, assim, corroborando com o entendimento já explicitado de que a aprendizagem com jogos digitais ocorre na experiência e nas relações interativas com o ambiente digital.

A relação com a escola é referenciada pelos jogadores, dois jogadores afirmam que aprenderam mais com o jogo do que com a escola e oito deles de que o jogo os ajudou ou pode ajudar na escola, enquanto dois jogadores relatam que, diferente dos jogos educativos, esse jogo não é chato.

Para autores como Gee (2003; 2010) e Squire (2011) todos os jogos digitais são educativos, já que o jogador precisa pelo menos aprender a jogar. Ao jogar é necessário compreender a narrativa, os desafios e as mecânicas, bem como aprimorar habilidades cognitivas e motoras. Entretanto, nota-se que na visão dos jogadores há diferença entre o que seria um "jogo educativo" e o que não seria. Eles citam a falta de desafios e diversão dos jogos digitais utilizados na escola, diferente dos jogos de entretenimento, que se tornam cada vez mais complexos e longos (Gee, 2003).

Nesse sentido, pondera-se se estes jogos são simplificados ao ponto de se tornarem algo muito parecido com o realizado e conhecido no ambiente escolar. Alguns motivos para tais ponderações, a saber: a falta de conhecimento dos professores em relação aos jogos digitais ou de recursos tecnológicos nas escolas, as diferenças de acesso entre os estudantes, o tempo de aula, a sobrecarga e desvalorização dos profissionais da educação, a cobrança avaliativa dos alunos, quando alguns professores e escola, ainda valorizam o conteudismo e a memorização.

O entendimento de que certos conteúdos e aprendizados não são "escolares" excluí formas diferentes de aprender e desconsidera assuntos do cotidiano e aprendizado de outras competências que se fazem presentes nos jogos (Gee, 2003).

Um jogador afirma que jogou o Plague inc. em aula e o jogador P464, que se identifica como um professor, descreve brevemente como utiliza o jogo digital em suas aulas: 
Eu na verdade uso esse jogo como uma pausa em um curso de graduação [...] Eu ensino biologia e projeto o jogo com o nosso retroprojetor e deixo os estudantes coletivamente fazer todas as escolhas do jogo. [...] Nós falamos sobre doenças reais, antivacina e mutações através do tempo enquanto jogamos. [...] Eu tento manter nossa discussão educativa, mas, ainda assim, divertida [...] (Jogador E464, 10 março de 2019, tradução das autoras).

O professor trabalha com o jogo de forma colaborativa, relacionando com eventos reais e gerando discussões entre alunos, uma atividade que pode auxiliar na promoção do pensamento crítico e compreensão da ciência como parte da sociedade (Gaydos \& Squire, 2012; Vieira \& Tenreiro-Vieira, 2014).

Na subcategoria "educativo sobre ciências biológicas", segunda em ocorrências, totalizando 69 falas, os jogadores afirmam considerar que o jogo ensina sobre temas relacionados a essa disciplina.

Maior parte dos jogadores, 33 no total, relatam o aprendizado sobre doenças e pandemias. O jogador BR14 afirma que:

Dá um excelente entendimento de uma pandemia real. Replica cenários do mundo real, como outras pandemias anteriores e até mesmo fake news. [...] Mais do que um jogo, uma verdadeira aula do que acontece quando uma pandemia estoura no mundo real, este jogo é altamente recomendado. [...] (Jogador BR714, 5 de abril de 2020).

Para 16 jogadores, simular e vivenciar doenças reais os ajudou a aprender mais sobre as mesmas, citam doenças como a peste-negra, H1N1, a mononucleose, a gripe aviária, a varíola, a doença da vaca louca e o próprio coronavírus. O jogador E701 considera o caráter educativo de poder simular doenças “....as pragas e doenças se relacionam com a história da humanidade". Assim, argumenta que o jogo tanto auxilia na compreensão sobre a biologia de diferentes patógenos quanto nos impactos sociais e culturais que uma pandemia pode causar. Nesse sentido, o jogador E401 aponta o benefício de poder visualizar as relações entre as variáveis socioeconômicas e climáticas dos países com as doenças pandêmicas simuladas.

A facilitação na visualização de diferentes variáveis presentes em fenômenos diversos é um dos potenciais de aprendizagem dos jogos digitais já reportados em estudos, como o realizado por Cheng e colaboradores (2018) utilizando o jogo Plague inc. com universitários em aulas de epidemiologia. Os autores relaram que o jogo auxiliou na compreensão sobre causa e efeito dos sintomas em relação ao tempo, além das características dos organismos infecciosos, a compreensão dos dados e suas representações gráficas. Nesse sentido, Corredor e colaboradores (2013) também reportam resultados positivos na sistematização e organização de processos biológicos pelos estudantes ao utilizar um jogo digital sobre infecções virais e afirmam que os alunos que jogaram tiveram mais facilidade de lembrar dos acontecimentos e estágios da infecção viral detalhadamente e em ordem cronológica.

O jogador E678 relata o aprendizado sobre adaptação biológica através do jogo. Além dele, outros dois jogadores comentam ter aprendido sobre mutações genéticas e quatro outros sobre evolução. Contudo, esses temas aparecem no jogo de forma simplificada e, até mesmo ilustrativa. Assim, ao usá-lo em aulas, o professor pode explorar os limites e erros conceituais por meio de discussões e atividades com 
alunos, para que não haja desentendimentos. O aprendizado de mutações genéticas, evolução e adaptação biológicas é descrito nos estudos de Sena (2016) e Costa e Ocelli (2020) que utilizaram o jogo Plague inc.

Nove jogadores registram o aprendizado sobre microrganismos, porém, generalizando, de forma simplista, como "doenças". O professor poderia lançar mão da ferramenta e discutir que não há dualidade - bem e mal - e sim papéis ecológicos desempenhados por esses organismos, enaltecendo suas diferenças biológicas.

Nesse contexto, o Plague inc. poderia possibilitar o entendimento do trabalho de cientistas, assim como a compreensão do impacto e papel desses profissionais na sociedade, conforme exemplo abaixo:

$\mathrm{Na}$ superfície você ganhará algum entendimento sobre como vários tipos de pragas se espalham e adaptam a novos ambientes e como sobre os métodos que os cientistas usam para diminuir a transmissão e acabar com elas. (Jogador E678, 4 de abril de 2015, tradução da autora)

Esse reconhecimento é um dos objetivos de uma educação em ciências que possibilite o estudante compreender a relação entre ciências, tecnologia e sociedade (Gaydos \& Squire, 2012; Tenreiro-Vieira \& Vieira, 2014).

Gee (2010) afirma que os bons jogos digitais funcionam como um ciclo que se assemelha a um experimento, onde o jogador cria uma hipótese, testa, avalia e reflete sobre os resultados. Cria outra hipótese, testa e dá sequência. Nesse contexto, os jogos digitais são exitosos no ensino de metodologia e pensamento científico (Morris et al., 2013; Mattar et al., 2017; Halpern et al., 2012). Segundo Diamond (2013), os jogadores acionam conhecimentos adquiridos pela memória de trabalho e armazenados, na memória de curto prazo, estabelecendo conexões.

Além disso, os jogadores relatam a conscientização em relação a problemas de saúde pública e prevenção de doenças, como afirmado pelo jogador PBR914, o jogo é "uma forma para jovens através do jogo aprenderem e se prevenirem de doenças" (Jogador PBR914, 16 de junho de 2015). Esse aprendizado também foi reportado por Nascimento e colaboradores (2020) e Alarcia (2015) ao utilizar o jogo Plague inc. com estudantes.

Considerando a pandemia de coronavírus e o consequente aumento da popularidade do Plague inc., não é surpresa que os jogadores o referenciem em suas avaliações. Sete jogadores relatam que aprenderam que o jogo pode servir de aprendizagem sobre a atual pandemia.

O jogador E603 comenta que há "tanta informação aqui...estou surpreso que nós não ainda conseguimos conter o coronavírus" (Jogador E603, 26 de junho de 2020, tradução da autora), enquanto o jogador E584, comenta que está trabalhando na linha de frente de combate ao coronavírus, faz uma reflexão sobre a sua experiência real e o que vivenciou através do jogo digital:

Contudo, jogar PI:E pode ser uma experiência catártica e educacional. [...] alguém pode aprender através de PI:E alguns fatores que podem contribuir ou não em uma pandemia. Se você tentar PI:E ou não, por favor fique seguro e saudável, e pratique distanciamento físico como parte de combater a pandemia de COVID-19. Escute os profissionais da saúde, e os ajude a fazer os 
seus trabalhos. Se PI:E pode ensinar alguma coisa ao público geral, seria que se comportando de outra maneira pode levar a cenários que são muito mais assustadores e letais. (Jogador E584, 28 de abril de 2020, tradução da autora)

Assim, reforça-se o entendimento dos jogos digitais como ambientes que viabilizam experiências, jogar um jogo sobre pandemias no atual cenário é um comportamento que pode estar relacionado ao desejo de compreensão da realidade, com algum tipo de controle e segurança. O jogador afirma que o jogo poderia ser utilizado para aprender como certas atitudes são essenciais em uma pandemia.

Na subcategoria "Educativo sobre outros conteúdos" dez jogadores registram aprenderam outros temas além de ciências biológicas, sendo que nove se referem ao aprendizado de geografia e um fala sobre matemática:

Todo mundo sabe que a progressão geométrica é rápida. Mas, nossa, jogando esse jogo você pode quase sentir os algoritmos por trás das cenas começarem a trabalhar quando você os alimenta com um pouco das suas mudanças. Eu diria que o jogo de algum modo pode te relembrar que a matemática pode ser realmente interessante. (Jogador E403, 4 de julho de 2018, tradução das autoras)

Entre os relatos associados a aprendizagem de geografia, dois jogadores comentam que é possível aprender acerca das características socioeconômicas dos países, quatro citam a aprendizagem de geografia de maneira geral e um fala sobre a visualização de mapas. Além disso, um jogador relata que o jogo o ajudou nas aulas de geografia.

A subcategoria "Reflexões sobre atitudes" possui 28 falas condizentes com mudanças de atitudes em relação à própria saúde que foram incentivadas pelo jogo, como, por exemplo, lavar as mãos e seguir as orientações da Organização Mundial da Saúde. O tema mais frequente entre esses relatos foi de que o jogo serve como um alerta para o quanto os humanos podem ser frágeis diante uma doença que se torna pandêmica $(n=9)$, onde o jogador BR366 afirma:

nele vc pode fazer o sonho de qualquer um descobrir como uma doença se espalha fazendo assim você tomar mais cuidado com a propria saude (Jogador BR366, 24 de novembro de 2018).

A pandemia do coronavírus é citada por três jogadores, todos em 2020, sendo que o jogador BR763 comenta que "Lava a mão e usa mascrinha caso contrário o corona levará sua vida :D" (Jogador PBR763, 2 de maio de 2020), em óbvia referência às medidas preventivas que devem ser tomadas durante a pandemia de coronavírus.

Nesse contexto, o movimento conspiracionista e anticientífico, antivacina foram tema em dez falas, sendo que o jogador E461 comenta que "depois de uma petição online, os desenvolvedores adicionarão os antivacina como um cenário. 10/10." (Jogador E461, 1 de março de 2019, tradução das autoras). Todos os comentários sobre a adição do movimento antivacina demonstravam o entendimento de que ele favoreceria a pandemia, atrapalhando os esforços feitos para contê-la.

Esse comportamento demonstra o engajamento dos jogadores com o jogo digital, ao se materializar em petição online e conseguir assinaturas para que algo que consideram relevante para o jogo seja adicionado. Inclusive, no fórum do jogo digital na Steam, um dos tópicos com mais respostas postadas é o criado pelo desenvolvedor 
do jogo pedindo sugestões para os jogadores. Assim, a comunidade se torna local de troca de experiências, construção de conhecimentos e do próprio jogo, gerando participação ativa dos jogadores e não apenas o consumo do que é apresentado.

Asubcategoria de "Interesse em ciências" tem menos falas relacionadas, três no total. Citamos o jogador E688 que diz "Nos próximos anos eu vou estudar microbiologia e imunologia [...] Ele não somente desperta meus interesses mas também é muito divertido." (Jogador E688, 21 de maio de 2015, tradução da autora). Ressaltamos a afirmação do jogador de que a diversão e o desafio são os motivos que o fazem gostar tanto do jogo, despertando seu interesse em ciências, inclusive o fazendo estudar uma área relacionada.

Ao analisar as abordagens dos jogadores, nota-se que o jogo digital pode promover a construção de conhecimento, reflexões sobre ciência e mudanças de atitudes, igualmente pode incentivar o interesse por carreiras científicas. Nesse sentido, o jogo poderia estimular um olhar para as ciências e sua relação com a sociedade sob uma nova perspectiva, assim, a partir dessa experiência, ao jogar, possam fazer "escolhas e intervenções conscientes e pautadas nos princípios da sustentabilidade e do bem comum (Ministério da Educação, p. 321, 2018). O professor pode utilizálo para gerar reflexão e debate acerca da presença da ciência na sociedade, como ocorrem as descobertas e pesquisas científicas, sobre as diversas variáveis presentes em um cenário pandêmico, entre outros assuntos que podem ser discutidos com e entre os estudantes.

A subcategoria com mais falas caracterizadas é "comunidade", onde 99 jogadores relatam aprendizados diversos na comunidade de jogadores, principalmente relacionados a produção de conteúdos, como criar e compartilhar cenários próprios, fazer vídeos de gameplay, guias de estratégia e, até mesmo a tradução do próprio jogo.

A ajuda com a tradução do jogo foi compartilhada por dois jogadores brasileiros, um deles afirma que outros membros da comunidade também são responsáveis pela versão do jogo em português do Brasil. Castells (2013) afirma que a comunidade se define na perspectiva de "fazer parte" da mesma, algo também apontado por Gee e Haynes (2012) sobre a comunidade de jogadores de The Sims. Os autores notam que os jogadores se engajavam nas práticas da comunidade, com produção de conteúdo e modificações para o jogo digital, além de ensinar sobre o jogo e tais práticas.

Há relatos de 59 jogadores sobre os benefícios da possibilidade de jogar e avaliar os cenários criados por outros jogadores, 6 deles citam produções feitas pela comunidade, como guias de estratégia. Esses comentários demonstram a relevância das produções para os jogadores:

O conteúdo gerado pela comunidade é provavelmente a melhor parte se você gosta de humor tolo e absurdo misturado com uma jogabilidade inteligente. (Jogador E12, 18 de fevereiro de 2016, tradução das autoras)

O criador de cenários permite que jogadores modifiquem variáveis do jogo, tais como, condições de vitória, clima de países, entre outros elementos e detalhes, utilizando a mecânica básica que envolve estourar bolhas para ganhar pontos e comprar progressões para alguma variável. Assim, o jogador precisa entender como 
o design do jogo funciona e como poderia expressar suas ideias a partir dessa base. A possibilidade de criar seus próprios cenários e compartilhá-los é citado de maneira positiva, 46 vezes.

Jacques (2015) discute o incentivo à criatividade, autoria e até o aprendizado sobre programação e design que o Plague inc. promove com a possibilidade de criação e partilha das fases no modo de criação de cenários. Ela aponta que os jogadores podem trazer conhecimentos e interesses baseados em suas experiências e criar fases não apenas sobre doenças, como, por exemplo, filosofia, política, guerras históricas e/ou cultura popular.

O uso da criatividade em atividades que não envolvem o uso do software diretamente é apontado por cinco jogadores. Mencionam que o jogo os inspira a escrever suas próprias histórias ou criar conteúdos, como blogs e vídeos no youtube.

$\mathrm{O}$ interesse nos jogos digitais pode influenciar os jogadores a tentarem criar seus próprios conteúdos, espaços e comunidades, incentivando o desenvolvimento de outros conhecimentos que vão além do conteúdo e temática do próprio jogo, como o uso de programas de filmagem, de edição de vídeo e roteirização (Gee \& Haynes, 2012). Dessa forma, discute-se que compartilhar suas criações com outros jogadores cria um sentimento de pertencimento, onde os jogadores se empoderam dos conteúdos e compartilham produções com uma comunidade que reúne "iguais".

Com esta abordagem histórica, observa-se que o jogo desenvolve habilidades que culminam em transformações, ou seja, mudanças de opinião sobre questões sanitárias, socioeconômicas, territorialidade, dentre outras. De maneira lúdica, engajada e despreocupada, os jogadores-aprendizes manifestam interesse pelo conhecimento científico, o papel da ciência na sociedade e sua relação com o cotidiano. Com ênfase é explicitada a construção da identidade por meio da exploração e curiosidade sobre os temas abordados, a possibilidade do "mão na massa" na criação própria de fases do jogo e na resolução dos problemas apresentados e, apreciam, sobretudo, as contribuições, partilhas e aprendizados realizadas com a comunidade.

\section{Considerações finais}

As narrativas dos jogadores que fundamentaram a categoria aprendizagem e suas subcategorias, conforme observado, possibilitam paralelos com os princípios de aprendizagem que, segundo Gee (2003; 2010), caracterizam os bons jogos digitais e podem ser indicados como dispositivos educacionais. Tais narrativas explicitam o entendimento dos jogadores de que o Plague inc. pode ser considerado educativo sob vários aspectos mesmo não que não tenha sido criado especificamente para uso escolar. Observa-se, ainda, que o jogo não fica circunscrito ao conteúdo de uma disciplina específica, trazendo à tona o caráter multidisciplinar essencial em estratégias pedagógicas que tenham foco nas relações das ciências, tecnologias e sociedade.

Nesse contexto, os relatos espontâneos dos jogadores indicam que aprenderam com o jogo conteúdos abordado no ensino formal, destacando-se uma série de temas como doenças, vacinas, microrganismos, mutação genética, evolução e a pandemia de coronavírus. Por óbvio, seria necessário um aprofundamento nos estudos para saber o que realmente aprenderam e como - a partir de quais mecânicas, interações sociais ou elementos presentes no jogo digital ou práticas da comunidade. No entanto, rela- 
tos sobre esses aprendizados, mudanças de atitude em relação à saúde e reflexões acerca de assuntos como saúde pública e papel da ciência na sociedade demonstram um potencial positivo do jogo digital Plague inc. como uma mídia de entretenimento que pode ser utilizada em práticas pedagógicas.

Outro ponto observado é como o lúdico do jogo digital ultrapassa as barreiras do software e os jogadores levam os conteúdos e experiências que vivenciam para outras plataformas e atividades de seu interesse, muitas vezes desenvolvendo habilidades e fomentando atitudes de forma tangencial. Estes interesses podem ser incentivados e mediados pelos professores ao utilizar jogos digitais em suas aulas, criando um ambiente de comunidade, onde os alunos-jogadores socializam suas aprendizagens e produções com seus pares. Além disso, jogos digitais, como Plague Inc., podem ser utilizados em práticas na sala de aula que ultrapassam o jogar, podendo ser utilizados em conjunto com atividades de análise crítica, debates e produções artísticas diversas. Assim, dentre os benefícios de aprendizagem observados destaca-se o caráter social dos jogos digitais, onde os relatos dos jogadores apontam aspectos positivos e relacionados com aprendizagens, tais como a comunicação, colaboração, criatividade e utilização de tecnologias para criação de conteúdos próprios.

Por fim, observa-se que tanto no jogo digital quanto na comunidade de jogadores, o estudante-jogador tem a possibilidade de compreender os problemas do entorno e desenvolver um percurso de aprendizagem próprio ao se debruçar em questões amplas, contextualizando cada situação e, consequentemente refletindo suas decisões e ações de forma situada. São experiências educacionais que reforçam a compreensão de que pessoas aprendem na intersubjetividade, mediadas pelo objeto de estudo e pelo mundo.

\section{Referências}

Alarcia, D. T. (2015). Plague Inc.: Pandemias, videojuegos y enseñanza-aprendizaje de las ciencias sociales. Innovaciones didácticas, 14, 135-142. https://bit.ly/3vIVTwE

Backes, L. A. (2011). Configuração do espaço de convivência digital virtual: A Cultura emergente no processo de formação do educador. Tese de Doutorado em Educação, Universidade do Vale do Rio dos Sinos, São Leopoldo, 362 p. https://bit.ly/316ZnOB

Bardin, L. (2011). Análise de conteúdo. São Paulo: Edições 70.

Castells, M. (2013). Redes de indignação e esperança: movimentos sociais na era da internet. Rio de Janeiro: Zahar.

Cheng, S., Egues, A. L. \& Cohen-Brown, G. (2018). Visualizing medicine: Mapping connections with Plague Inc. to learn in the interdisciplinary classroom. En: R. D. Lansiquot, S. P. Macdonald (Eds), Interdisciplinary Place-Based Learning in Urban Education (pp. 111-132), New York: Palgrave MacMillan.

Clark, D. B., Tanner-Smith, E. E. \& Kollingsworth, S. S. (2016). Digital games, design and learning: A systematic review and Meta-Analysis. American Educational Research Association, 86(1), 79-122. https://www.doi.org/10.3102/0034654315582065

Corredor, J., Squire, K. \& Gaydos, M. (2013). Seeing change in time: Video games to teach about temporal change in scientific phenomena. Journal of Science Education \& Technology, 3(3), 324-343. https://www.doi.org/10.1007/s10956-013-9466-4 
Costa, G. M. D. \& Occelli, M. (2020). Análisis de simulaciones computacionales para la enseñanza del modelo de evolución biológica por selección natural. Revista Eureka sobre Enseñanza y Divulgación de las Ciencias, 17(2), 2201-2222. https://doi.org/10.25267/Rev_Eureka_ ensen_divulg_cienc.2020.v17.i2.2201

Diamond, A. (2013). Executive Functions. Annual review of psychology, 64(1), 135-168. https://www. doi.org/10.1146/annurev-psych-113011-143750.

Eck, R. N. V. (2015). Digital game-based learning: Still restless after all these years. Educause Review, 50(6), 13. https://bit.ly/3jER7eR

Gaydos, M. J. \& Squire, K. (2012). Role playing games for scientific citizenship. Cultural Studies of Science Education, 7(4), 821-884. https://www.doi.org/10.1007/BF02504859

Gee, J. P. (2003). What videogames have to teach us about learning and literacy. Nova lorque: Palgrave Macmillan.

Gee, J. P. (2010). Bons Videojogos + Boa Aprendizagem: Colectânea de Ensaios sobre os Videojogos, a Aprendizagem e a Literacia. Portugal: Contrapontos.

Gee, J. P. \& Haynes, E. (2012). NurturingAffinity Spaces and Game-Based Learning. In: C. Steinkuehle, K. Squire, S. Barab (Eds). Games, Learning and Society (129-153), Londres: Cambridge University Press.

Halpern, D. F., Millis, K., Graesser, A. C., Butler, H., Forsynth, C. \& Cai, Z. (2012) Operation ARA: A computerized learning game that teaches critical thinking and scientific reasoning. Thinking Skills and Creativity, 7, 93-100. https://www.doi.org/10.1016/j.tsc.2012.03.006

Jacques, L. A. (2015). An analysis of Plague, Inc: Evolved for learning. In: D. Davidson (Ed). Well played:Ajournal on videogames, values and meaning (112-25), Estados Unidos: Carnegie Mellon University ETC Press.

Mattar, J., Souza, A. L. M. \& Beduschi, J. O. (2017). Games para o ensino de metodologia científica: revisão de literatura e boas práticas. Educação, Formação \& Tecnologias, 10(1), 3-19. https://bit.ly/3jFvzPh

Ministério da Educação. (2018). Base nacional comum curricular. Brasil: UNDIME - União Nacional dos Dirigentes Municipais de Educação, CONSED: Conselho Nacional de Secretários de Educação. http://basenacionalcomum.mec.gov.br/

Nascimento, F. G. M., Benedetti, T. R. \& Santos, A. R. (2020). Uso do Jogo Plague Inc.: uma possibilidade para o Ensino de Ciências em tempos da COVID-19. Brazilian Journal of Development, 6(5), 25909-25928. https://www.doi.org/10.34117/bjdv6n5-156

Morris, B. J., Croker, S., Zimmerman, C., Gill, D. \& Romig, C. (2013). Gaming science: the "Gamification" of scientific thinking. Frontiers in Psychology, 4(607), 1-16. https://www.doi.org/10.3389/ fpsyg.2013.00607

Ramos, D. K. (2013). Jogos cognitivos eletrônicos: contribuições à aprendizagem no contexto escolar. Ciências \& Cognição, 18(1), 19 -32.

Recuero, R. C. (2001). Comunidades virtuais - Uma abordagem teórica. In: V Seminário Internacional de Comunicação. PUC/RS, s/data. http://www.raquelrecuero.com/teorica.htm.

Sakuda, L. O. \& Fortim, I. (Orgs.). (2018). I/ Censo da Indústria Brasileira de Jogos Digitais. Ministério da Cultura: Brasília. https://bit.ly/3pDXhjh

Santos, F. M. (2012). Análise de conteúdo: a visão de Laurence Bardin. Resenha de: [Bardin, L. (2011). Análise de conteúdo. São Paulo: Edições 70] Revista Eletrônica de Educação - UFSCar, 6(1), 383-387. https://www.doi.org/10.14244/2519827199291

Salen, K. \& Zimmerman, E. (2012). Regras do jogo: Fundamentos do design de jogos. Volume 1. São Paulo: Blucher.

Schuytema, P. (2017). Design de games: uma abordagem prática. São Paulo: Cengage.

Sena, C. M. (2016). Plague INC.: Jogo de simulação de pandemias auxiliando no estudo dos vírus, bactérias e fungos. Tecendo Educação: Seminário de Boas Práticas 2016, pp. 9-10. https://bit.ly/3GmWwkB 
Squire, K. (2011). Video games and learning: Teaching and participatory culture in the digital age. New York: Teachers College Press.

Tobias, S., Fletcher, J. D. \& Wind, A. P. (2014). Game-Based Learning. In: J. M. Spector (Ed.). Handbook of research on educational communications and technology. New York: Springer.

Tönnies, F. (1973). Comunidade e sociedade como entidades típico-ideais. In: Fernandes, F. (Org.). Comunidade e sociedade: leituras sobre problemas conceituais, metodológicos e de aplicação. São Paulo: Editora Nacional e Editora da USP, p. 96-116.

Vieira, R. M. \& Tenreiro-Vieira, C. (2014). Investigação sobre o pensamento crítico na educação: contributos para a didática de ciências. En R. M. Vieira, C. Tenreiro-Vieira, I. Sá-Chaves e C. Machado (Orgs). Pensamento crítico na educação: perspectivas atuais no panorama internacional (41-56) Aveiro: UA Editora.

Zagal, J. P. (2008) A framework for games literacy and understanding games. Proceedings of the 2008 Conference on Future Play: Research, Play, Share, Future Play 2008 Canada, p. 33-40. https://www.doi.org/10.1145/1496984.1496991

Zimmerman, E. (2007). Gaming Literacy: Game Design as a Model for Literacy in the 21st Century. Harvard Interactive Media Review, 1(1), 30-5.

\section{Cómo citar en APA:}

Ramos, D. K., Rúbia, T. e De Brito, C. R. (2021). Aprendizagem de ciências no jogo digital Plague Inc.:análise de conteúdo em uma comunidade de jogadores. Revista Iberoamericana de Educación, 87(2), 51-65. https://doi.org/10.35362/rie8724556 